\title{
Cardiotoxicity in Acute Zinc Phosphide Intoxicated Patients (A Prospective Study)
}

\author{
Aya S. Khater and Nesrine M. Sarhan ${ }^{1}$
}

${ }^{1}$ Forensic Medicine and Clinical Toxicology Department, Faculty of Medicine, Ain-Shams University, Cairo, Egypt

\begin{abstract}
Phosphides are common pesticides widely used as a grain preservative. Zinc phosphide toxicity is a major health problem with a high mortality rate especially in developing countries. Cardiotoxicity is the main cause of death in phosphide poisonings. Aim of study: This prospective study aimed to evaluate the cardiovascular affection among zinc phosphide intoxicated patients admitted to the Poison Control Center, Ain Shams University Hospitals (PCC- ASUH) during the period from $1^{\text {st }}$ June 2013 to $1^{\text {st }}$ June 2014 and to determine factors predicting the outcome of patients with zinc phosphide cardiotoxicity with special reference to determination of serum troponin I.

Methods: Clinical characteristics (systolic blood pressure and central venous pressure), laboratory parameters (liver enzymes, renal function, serum electrolytes: (sodium and potassium), random blood sugar, serum bicarbonate and qualitative assessment of cardiac troponin I, electrocardiographic ( ECG) findings and treatment characteristics were all recorded.

Results: Cardiotoxicity was evident in 18 patients out of 144 (12.5\%) with zinc phosphide intoxication, twelve of them died. Systolic blood pressure was significantly lower among non survivors $(60 \pm 7 \mathrm{mmHg})$ compared to survivors $(75 \pm 5 \mathrm{mmHg})$. Central venous pressure was elevated in 6 patients, all of them died. Serum cardiac troponin I was positive in $67 \%$ (12 patients) and it did not predict mortality. Eight patients out of the 18 patients had dysrhythmias which found to be a predictor of mortality.

Conclusion: The statistically significant factors useful in predicting mortality in our study were shock (which required vasoactive drugs), increased central venous pressure and ventricular arrhythmias.
\end{abstract}

\section{Introduction}

$\mathrm{P}$ hosphides are common pesticides widely used as a grain preservative. It is a major health problem with a high mortality rate especially in developing countries because of its low cost and easy accessibility (Mehrpour et al., 2008 and Louriz et al., 2009). Zinc phosphide is emerging as a common selfpoisoning agent in Egypt (El Naggar and El Mahdy, 2011).

In 2012, zinc phosphide represented about $0.01 \%$ (196 of 19744 cases) of the cases presented to the Poison Control Center, Ain Shams University Hospitals; (PCC-ASUH) however, it represented about $16 \%$ (5 of 30 cases) of the mortality cases (Halawa et al., 2013)

Cardiotoxicity is a significant cause of death in phosphide poisonings (Jadhav et al., 2012). It manifests as refractory hypotension, congestive heart failure and $/$ or electrocardiographic (ECG) abnormalities and elevation of cardiac markers, such as creatine phosphokinase- MB (CPK-MB) fraction (Nakakita et al., 2009).

\section{The aim of the study}

Is to evaluate the magnitude of cardiovascular affection among zinc phosphide intoxicated patients presented to the PCC-ASUH during the period from $1^{\text {st }}$ June 2013 to $1^{\text {st }}$ June 2014 and to assess the role of some investigational parameters as predictors for the outcome in these patients with special reference to serum troponin I.

\section{Subjects and Methods}

\section{Subjects}

Eighteen patients were selected from all patients with acute zinc phosphide intoxicated patients presented to PCC-ASUH during the period from $1^{\text {st }}$ June 2013 to $1^{\text {st }}$ June 2014 and were prospectively investigated for evidence of cardiovascular affection by the presence of hypotension and /or electrocardiographic (ECG) changes. The diagnosis of phosphide intoxication was based preliminary on history of consumption of the 
fine black powder rodenticide (Bumbrah et al., 2012) obtained from the patient or his relatives, and manifestations on admission.

\section{Exclusion criteria}

Patients presented with unclear diagnosis of poisoning, consumption of more than one substance or those with previous history of cardiovascular disorders as well as patients with risk factors such as hypertension, diabetes or smoking were all excluded from the study.

Patients were divided into 2 groups, according to their mortality outcome:

The first group: (Survivors) and the second group: (Non Survivors)

\section{Ethical Considerations}

Approval of the Ethical Committee and the Head of the PCC-ASUH were obtained. Informed consents were also obtained from the patients or their relatives. They were assured that any information they provided would be kept strictly confidential and anonymous.

\section{Methods}

I) Data collection

1. Demographic data

- Demographic data: age, sex, occupation and residence.

2. Intoxication data

- Route of poisoning.

- Manner of poisoning.

- Delay time between intoxication and arrival to PCC-ASUH.

3. Clinical data for cardiac affection: (systolic blood pressure and central venous pressure). Normal central venous pressure: $(8-20 \mathrm{~cm}$ $\mathrm{H}_{2} \mathrm{O}$ ) (Marino, 2010).

4. Treatment

Gastric lavage (according to patient's hemodynamic status) was performed to patients who presented within the first two hours of intoxication. Then they received oral sodium bicarbonate (Proudfoot, 2009).

Intravenous fluids were administered for resuscitation of patients. Inotropic drugs such as dopamine $(20 \mu \mathrm{g} / \mathrm{kg} / \mathrm{min})$ or dobutamine (10 $\mu \mathrm{g} / \mathrm{kg} / \mathrm{min}$ ) (Marino, 2010) and antiarrythmics drugs were given to all of them. Mechanical ventilation was instituted if indicated. All patients were admitted into intensive care unit (ICU).

\section{II) Studied parameters}

\section{1) Laboratory parameters}

- Liver enzymes: aspartate aminotransferase (AST) (Normal range: up to $37 \mathrm{U} / \mathrm{L}$ ) and alanine aminotransferase (ALT) (Normal range: up to $42 \mathrm{U} / \mathrm{L}$ ) (Nyblom et al., 2006).

- Renal function: serum creatinine (Normal range: up to $1.4 \mathrm{mg} / \mathrm{dl}$ ) (Bazari, 2007) and urea (Normal range: 10- $50 \mathrm{mg} / \mathrm{dl}$ ) (Sue and Vintch, 2005)

- Serum electrolytes: serum sodium (Normal range: $135-150 \mathrm{mEq} / \mathrm{L})$ and serum potassium (Normal range: $3.5-5.5 \mathrm{mEq} / \mathrm{L}$ )
(Faix, 2000), random blood sugar (Normal range: 72- $144 \mathrm{mg} / \mathrm{dl}$ ) (Lehman and Krumholz, 2009) and sodium bicarbonate (Normal: 22-26 mEq/L) (Cox, 2001).

- Qualitative assessment of cardiac troponin I (CAL-Tech Diagnostics, Inc Chino, California, USA).

2) ECG: An initial was recorded and repeated when required.

\section{III) Statistical Analysis}

The SPSS (Statistical Package for the Social Science) version 13, computer program was used. $P<0.05$ was considered significant. $P<0.001$ was considered highly significant.

\section{Results}

Cardiotoxicity was evident in 18 patients presented with zinc phosphide intoxication during the study period. Twelve cases of them died, death occurred within mean $16 \pm 12$ hours from the time of zinc phosphide ingestion.

The mean age of patients was $31 \pm 7$ years. Table (1) represents that females were predominant than males, $50 \%$ of cases were unemployed, about $28 \%$ were laborers while 4 cases were employed. Eighty three percent of cases were from urban areas while about $17 \%$ were from rural areas. Oral ingestion was the main route and inhalation poisoning occurred during pesticide application on grains in one case only. As regards the manner of poisoning; suicide was the main manner of poisoning in all cases except the case in which accidental exposure occurred during pesticide application on grains. Most of the patients were presented with delay time between 6-8 hours.

\section{Clinical manifestations at presentation:}

Nausea and vomiting were the initial manifestations in 13 patients $(72 \%)$, abdominal colic was found in 11 patients (61\%), while agitation was the first manifestation in 10 patients $(55 \%)$. All of them were oriented and fully conscious.

Mean systolic blood pressure was low in all cases $(65 \pm 10) \mathrm{mmHg}$, but it was significantly lower in non survivors $(60 \pm 7) \mathrm{mmHg}$ compared to those who survived $(75 \pm 5) \mathrm{mmHg}$, (Table 2). Diastolic blood pressure was barely auscultated.

Central venous pressure was elevated in 6 patients (33\%), all of them died. There was significant difference between both groups as regards central venous pressure (Table 3).

\section{Laboratory findings}

Increased serum levels of AST (165.5 $\pm 45.7 \mathrm{U} / \mathrm{L}$ for the survivors and 127.25 $\pm 83.35 \mathrm{U} / \mathrm{L}$ for the non survivors) and ALT $(104 \pm 32 \mathrm{U} / \mathrm{L}$ for the survivors and $105.92 \pm 70.58 \mathrm{U} / \mathrm{L}$ for the non survivors) were observed in all patients. Serum urea was statistically indifferent between both groups $(44 \pm 9.96 \mathrm{mg} / \mathrm{dL}$ for the survivors and $40.67 \pm 4.05 \mathrm{mg} / \mathrm{dL}$ for the non survivors). Also, there was insignificant difference between serum creatinine in both groups $(1.2 \pm 0.37$ $\mathrm{mg} / \mathrm{dL}$ for the survivors and $1.05 \pm 0.24 \mathrm{mg} / \mathrm{dL}$ for the non survivors) (Table 4). 
Although mean serum bicarbonate was lower in non survivors group $11.75 \pm 3.25 \mathrm{mEq} / \mathrm{L}$ compared to the survivors $(13 \pm 1.1 \mathrm{mEq} / \mathrm{L})$, yet this was not statistically significant (Table 4).

Table 4 also shows that both groups of patients under the study had normal mean serum levels of sodium $(\mathrm{Na}+)(136.50 \pm 1.64 \mathrm{mEq} / \mathrm{L}$ for the survivors and $136.75 \pm 2.01 \mathrm{mEq} / \mathrm{L}$ for the non survivors), mean serum potassium $(\mathrm{K}+)(3.95 \pm 0.16 \mathrm{mEq} / \mathrm{L}$ for the survivors and $3.90 \pm 0.20 \mathrm{mEq} / \mathrm{L}$ for the non survivors), and mean random blood sugar (RBS) was $(105.33 \pm 11.33 \mathrm{gm} / \mathrm{dL}$ for the survivors and $128.50 \pm 52.53 \mathrm{gm} / \mathrm{dL}$ for the non survivors).

Table 5 shows that serum cardiac troponin I was positive in 12 patients $(66.7 \%)$, which did not predict mortality as no significant difference was found between both groups as regards the presence of cardiac troponin I.

\section{Electrocardiographic findings}

Eight patients out of the 18 patients included in the current study had dysrhythmias, in the form of wide complex ventricular tachycardia, atrial fibrillation, diffuse ST segment elevation or abnormal repolarization in the form of (inverted $\mathrm{T}$ wave) as presented on ECG (Table 6 and figures 1, 2, 3 and 4). The presence of electrocardiographic abnormalities predicted mortality (Table7).

\section{Treatment and outcome}

Gastric lavage was performed in 7 patients. All of them received sodium bicarbonate. All of the 18 patients were hypotensive despite adequate fluid resuscitation and required vasoactive support, predominantly dopamine and dobutamine (Table 8).

Mechanical ventilation was required in 6 patients $(33 \%)$ whom all died (Table 9 ).

For prediction of zinc phosphide induced cardiotoxicity, the analysis showed that, increased central venous pressure (CVP) had the highest sensitivity (100\%) and specificity $(100 \%)$ and followed by shock represented by decreased systolic blood pressure with sensitivity (75\%) and specificity (100\%). ECG found to have sensitivity $(66.7 \%)$ and with $(100 \%)$ specificity. Cardiac troponin I shows non significance value as a predictor of cardiac involvement (Table 10).

Table (1): Percentage of distribution of demographic and intoxication data in patients admitted to PCC-ASUH with acute zinc phosphide induced cardiotoxicity.

\begin{tabular}{|l|c|c|}
\hline \multicolumn{1}{|c|}{ Description } & $\begin{array}{c}\text { Number } \\
(\mathbf{N})\end{array}$ & $\begin{array}{c}\text { Percentage } \\
(\boldsymbol{\%})\end{array}$ \\
\hline Sex & 13 & 72.2 \\
Female & 5 & 27.8 \\
Male & 18 & 100 \\
\hline Total & & \\
\hline Occupation & 9 & 50 \\
Unemployed & 5 & 27.8 \\
Laborers & 4 & 22.2 \\
Employed & 18 & 100 \\
\hline Total & & \\
\hline Residence & 15 & 83.3 \\
Urban areas & 3 & 16.7 \\
Rural areas & 18 & 100 \\
\hline Total & & \\
\hline Route of poisoning & 17 & 94.4 \\
Oral route & 1 & 5.6 \\
Inhalation & 18 & 100 \\
\hline Total & & \\
\hline Manner of poisoning & 17 & 94.4 \\
Suicidal & 1 & 5.6 \\
Accidental & 18 & 100 \\
\hline Total & & \\
\hline
\end{tabular}

Table (2): Student " $t$ " test comparing mean systolic blood pressure in patients admitted to PCC-ASUH with acute zinc phosphide induced cardiotoxicity (Survivors versus Non Survivors).

\begin{tabular}{|l|c|c|c|c|}
\hline \multicolumn{1}{|c|}{ Patient groups } & $\begin{array}{c}\text { Systolic blood } \\
\text { pressure (mmHg) } \\
\text { Mean + SD }\end{array}$ & Range (mmHg) & t-test & p-value \\
\hline Survivors (N=6) & $75 \pm 5$ & $70-80$ & 4.382 & $<0.001 *$ \\
\hline Non Survivors (N=12) & $60 \pm 7$ & $50-70$ & \\
\hline
\end{tabular}

$* P<0.001$ is considered highly significant, $N:$ Number 
Table (3): Fisher's exact test comparing central venous pressure in patients admitted to PCC-ASUH with acute zinc phosphide induced cardiotoxicity (Survivors versus Non Survivors).

\begin{tabular}{|l|c|c|c|c|c|c|c|}
\hline & \multicolumn{2}{|c|}{ Survivors } & \multicolumn{2}{|c|}{ Non Survivors } & \multicolumn{2}{|c|}{ Total } & \multirow{2}{*}{ P-value } \\
\cline { 2 - 7 } & $\mathbf{N}$ & $\mathbf{\%}$ & $\mathbf{N}$ & $\mathbf{\%}$ & $\mathbf{N}$ & $\mathbf{\%}$ & \\
\hline Decreased & 0 & $0 \%$ & 6 & $50 \%$ & 6 & $33.3 \%$ & \multirow{2}{*}{$<0.001 *$} \\
\hline Normal & 6 & $100 \%$ & 0 & $0 \%$ & 6 & $33.3 \%$ & \\
\hline Increased & 0 & $0 \%$ & 6 & $50 \%$ & 6 & $33.3 \%$ & \\
\cline { 1 - 6 } Total & 6 & $100 \%$ & 12 & $100 \%$ & 18 & $100.0 \%$ & \\
\hline
\end{tabular}

$* P<0.001$ is considered highly significant, $N$ : number

Table (4): Student " $t$ " test comparing laboratory parameters in patients admitted to PCC-ASUH with acute zinc phosphide induced cardiotoxicity (Survivors versus Non Survivors).

\begin{tabular}{|l|c|c|c|c|c|c|}
\hline \multirow{2}{*}{ Laboratory parameter } & \multicolumn{2}{c|}{ Survivors $(\mathbf{N}=\mathbf{6})$} & \multicolumn{2}{c|}{ Non Survivors $(\mathbf{N}=\mathbf{1 2})$} & \multicolumn{2}{c|}{ Independent t-test } \\
\cline { 2 - 7 } & Mean \pm SD & Range & Mean \pm SD & Range & T & p-value \\
\hline AST (U/L) & $165.5 \pm 45.7$ & $120-211$ & $127.25 \pm 83.35$ & $49-245$ & 0.532 & 0.31 \\
\hline ALT (U/L) & $104 \pm 32$ & $77-135$ & $105.92 \pm 70.58$ & $36-200$ & -0.679 & 0.97 \\
\hline Urea (mg/dL) & $44 \pm 9.96$ & $32-57$ & $40.67 \pm 4.05$ & $38-48$ & 0.907 & 0.28 \\
\hline Creatinine (mg/dL) & $1.2 \pm 0.37$ & $0.8-1.6$ & $1.05 \pm 0.24$ & $0.8-1.4$ & 0.89 & 0.26 \\
\hline Serum bicarbonate (mEq/L) & $13.00 \pm 1.10$ & $12-14$ & $11.75 \pm 3.25$ & $7-15$ & 0.904 & 0.379 \\
\hline Serum sodium (mEq/L) & $136.50 \pm 1.64$ & $135-138$ & $136.75 \pm 2.01$ & $135-140$ & -0.263 & 0.796 \\
\hline Serum potassium (mEq/L) & $3.95 \pm 0.16$ & $3.8-4.1$ & $3.90 \pm 0.20$ & $3.7-4.2$ & 0.537 & 0.599 \\
\hline RBS gm/dl & $105.33 \pm 11.33$ & $95-116$ & $128.50 \pm 52.53$ & $92-215$ & -1.053 & 0.308 \\
\hline
\end{tabular}

$P>0.05$ is considered insignificant, $N$ : number, RBS: Random blood sugar

Table (5): Fisher's exact test comparing cardiac troponin I in patients admitted to PCC-ASUH with acute zinc phosphide induced cardiotoxicity (Survivors versus Non Survivors).

\begin{tabular}{|l|c|c|c|c|c|c|c|}
\hline \multirow{2}{*}{ Outcome } & \multicolumn{2}{|c|}{ Survivors } & \multicolumn{2}{|c|}{ Non Survivors } & \multicolumn{2}{|c|}{ Total } & \multirow{2}{*}{ P-value } \\
\cline { 2 - 7 } & $\mathbf{N}$ & $\boldsymbol{\%}$ & $\mathbf{N}$ & $\boldsymbol{\%}$ & $\mathbf{N}$ & $\boldsymbol{\%}$ & \\
\hline Negative & 0 & $0.0 \%$ & 6 & $50.0 \%$ & 6 & $33.3 \%$ & \\
\hline Positive & 6 & $100.0 \%$ & 6 & $50.0 \%$ & 12 & $66.7 \%$ & \multirow{2}{*}{$0.054 *$} \\
\hline Total & 6 & $100.0 \%$ & 12 & $100.0 \%$ & 18 & $100.0 \%$ & \\
\hline
\end{tabular}

$* P>0.05$ is considered insignificant, $N$ : number, $\%$ : percentage

Table (6): ECG abnormalities in patients admitted to PCC-ASUH with acute zinc phosphide induced cardiotoxicity.

\begin{tabular}{|l|c|c|}
\hline ECG abnormalities & $\mathrm{N}$ & $\%$ \\
\hline Wide complex ventricular tachycardia & 4 & 50 \\
\hline Atrial fibrillation & 1 & 12.5 \\
\hline Diffuse ST segment elevation & 2 & 25 \\
\hline Abnormal repolarization (inverted T wave) & 1 & 12.5 \\
\hline Total & 8 & 100 \\
\hline
\end{tabular}

N: Number, \%: percentage

Table (7): Fisher's exact test of ECG changes in patients admitted to PCC-ASUH with acute zinc phosphide induced cardiotoxicity (Survivors versus Non Survivors).

\begin{tabular}{|l|c|c|c|c|c|c|c|}
\hline \multirow{2}{*}{ ECG abnormality } & \multicolumn{2}{|c|}{ Survivors } & \multicolumn{2}{|c|}{ Non Survivors } & \multicolumn{2}{|c|}{ Total } & \multirow{2}{*}{ P-value } \\
\cline { 2 - 7 } & $\mathbf{N}$ & $\mathbf{\%}$ & $\mathbf{N}$ & $\mathbf{\%}$ & $\mathbf{N}$ & $\mathbf{\%}$ & \\
\hline Normal & 6 & $100.0 \%$ & 4 & $33.3 \%$ & 10 & $55.6 \%$ & \multirow{2}{*}{$0.013 *$} \\
\hline Abnormal & 0 & $0.0 \%$ & 8 & $66.7 \%$ & 8 & $44.4 \%$ & \\
\hline Total & 6 & $100.0 \%$ & 12 & $100.0 \%$ & 18 & $100.0 \%$ & \\
\hline
\end{tabular}

$* P<0.05$ is considered significant, $N:$ number, $\%$ : percentage

Table (8): Fisher's exact test of vasoactive drugs administration in patients admitted to PCC-ASUH with acute zinc phosphide induced cardiotoxicity (Survivors versus Non Survivors).

\begin{tabular}{|l|c|c|c|c|c|c|c|}
\hline \multirow{2}{*}{ Vasoactive drug } & \multicolumn{2}{|c|}{ Survivors } & \multicolumn{2}{|c|}{ Non survivors } & \multicolumn{2}{|c|}{ Total } & \multirow{2}{*}{ P-value } \\
\cline { 2 - 8 } & No. & $\%$ & No. & \% & No. & \% & \\
\hline Dopamine & 6 & $100.0 \%$ & 6 & $50.0 \%$ & 12 & $66.7 \%$ & \multirow{2}{*}{$0.054 *$} \\
\hline Dopamine, dobutamine & 0 & $0.0 \%$ & 6 & $50.0 \%$ & 6 & $33.3 \%$ & \\
\cline { 1 - 7 } Total & 6 & $100.0 \%$ & 12 & $100.0 \%$ & 18 & $100.0 \%$ & \\
\hline
\end{tabular}

$* P>0.05$ is considered insignificant, $N:$ number, $\%:$ percentage. 
Table (9): Fisher's exact test of patients admitted to PCC-ASUH with acute zinc phosphide induced cardiotoxicity who required mechanical ventilation (Survivors versus Non Survivors).

\begin{tabular}{|l|c|c|c|c|c|c|c|}
\hline & \multicolumn{2}{|c|}{ Survivors } & \multicolumn{2}{|c|}{ Non Survivors } & \multicolumn{2}{|c|}{ Total } & \multirow{2}{*}{ P-value } \\
\cline { 2 - 7 } & $\mathbf{N}$ & $\%$ & $\mathbf{N}$ & $\%$ & $\mathbf{N}$ & $\%$ & \\
\hline $\begin{array}{l}\text { Did not require } \\
\text { mechanical ventilation }\end{array}$ & 6 & $100.0 \%$ & 6 & $50.0 \%$ & 12 & $66.67 \%$ & \\
\cline { 1 - 7 } $\begin{array}{l}\text { Required mechanical } \\
\text { ventilation }\end{array}$ & 0 & $0.0 \%$ & 6 & $50.0 \%$ & 6 & $33.33 \%$ & $0.054^{*}$ \\
\cline { 1 - 7 } Total & 6 & $100.0 \%$ & 12 & $100.0 \%$ & 18 & $100.0 \%$ & \\
\hline
\end{tabular}

$* P>0.05$ is considered insignificant, $N:$ number, $\%:$ percentage.

Table (10): Sensitivity and specificity of CVP, systolic blood pressure, ECG and cardiac troponin I among patients admitted to PCC-ASUH with acute zinc phosphide induced cardiotoxicity.

\begin{tabular}{|l|c|c|c|c|}
\hline & Sensitivity & Specificity & AUC & Accuracy \\
\hline CVP & 100 & 100 & 100 & 100 \\
\hline Systolic BP & 75 & 100 & 93.7 & 87.5 \\
\hline ECG & 66.7 & 100 & 83.3 & 83.35 \\
\hline Cardiac Troponin I & 50 & 100 & 75 & 75 \\
\hline
\end{tabular}

CVP: Central venous pressure

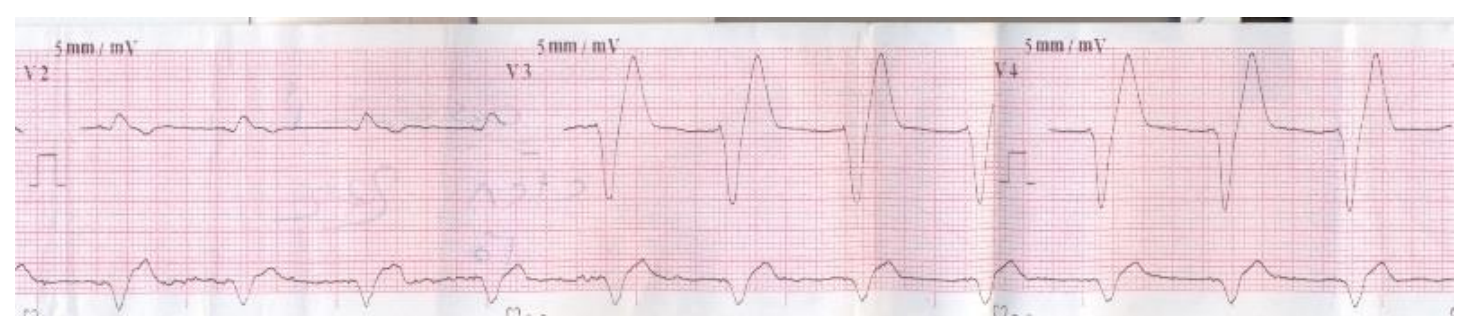

Figure (1): A strip of ECG of a 38-year-old male patient acutely intoxicated with zinc phosphide, his systolic blood pressure $50 \mathrm{mmHg}$ shows wide complex ventricular tachycardia.

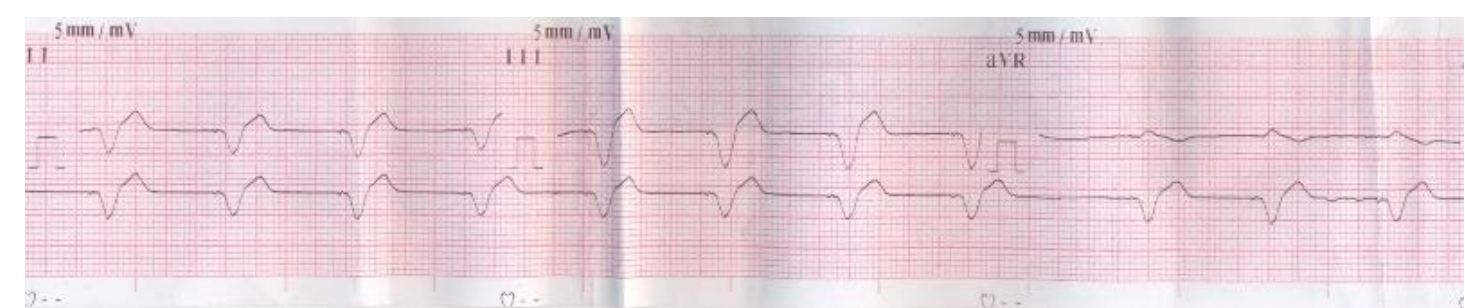

Figure (2): A strip of ECG of a 31 - year-old male patient, acutely intoxicated with zinc phosphide, his systolic blood pressure was $60 \mathrm{mmHg}$ shows wide complex ventricular tachycardia.

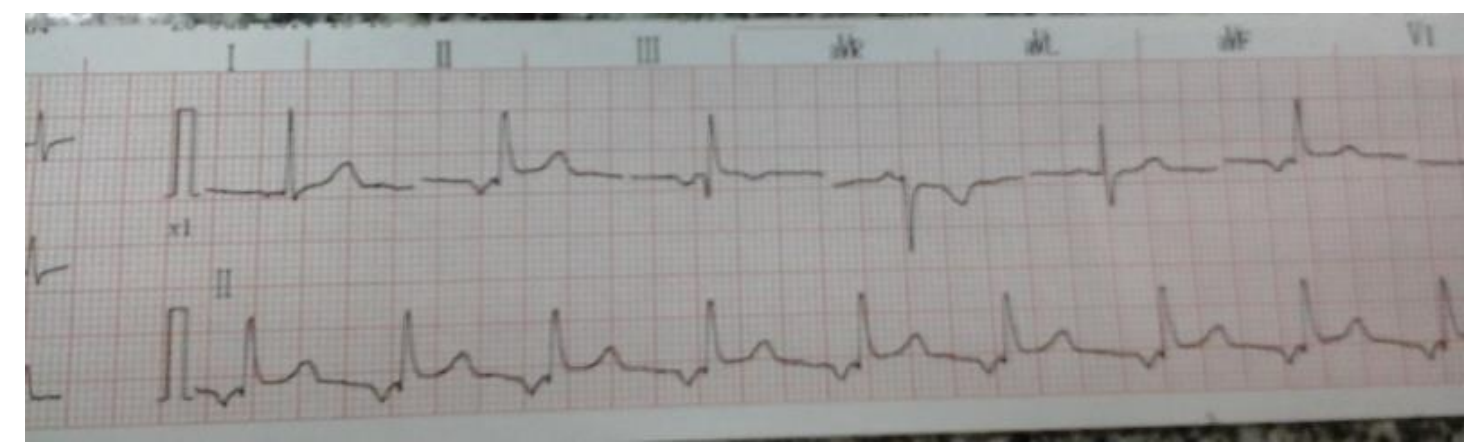

Figure (3): A strip of ECG of 23 - year-old female patient acutely intoxicated with zinc phosphide, her systolic blood pressure was70 $\mathrm{mmHg}$ shows diffuse ST segment elevation. 


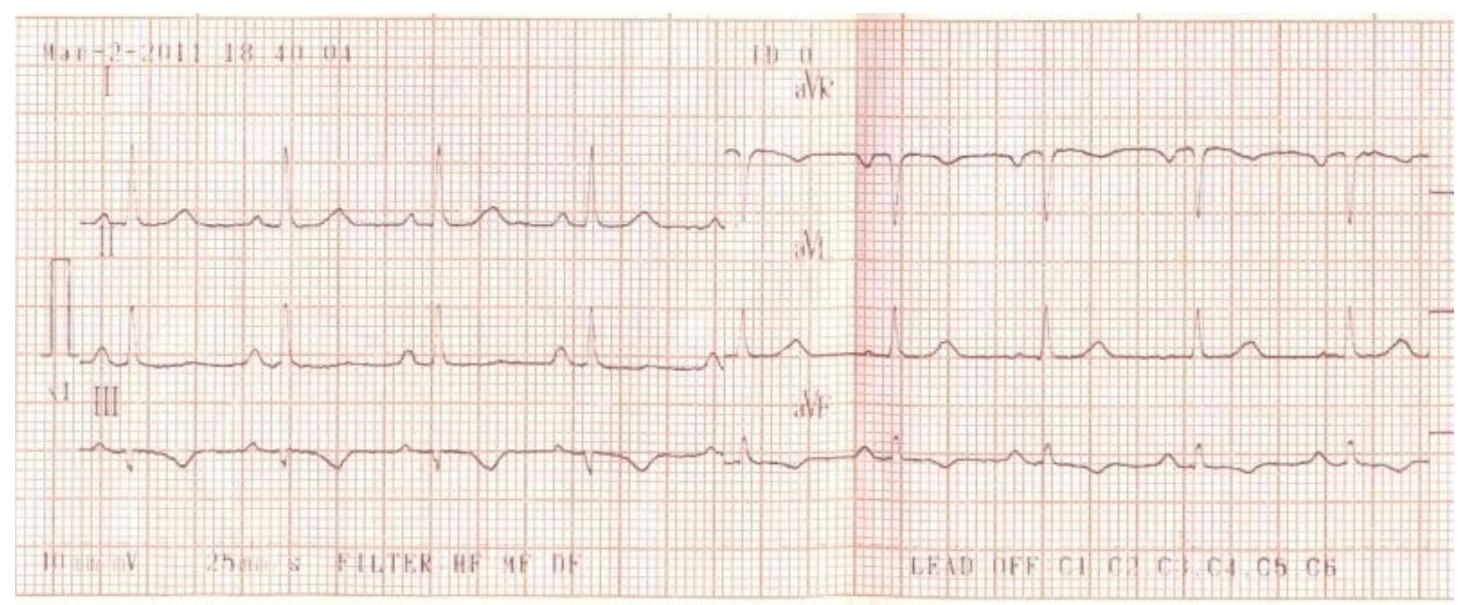

Figure (4): A strip of ECG of a 34 - year-old female patient acutely intoxicated with zinc phosphide, her systolic blood pressure $70 \mathrm{mmHg}$ shows abnormal repolarization in the form of inverted $\mathrm{T}$ wave.

\section{Discussion}

As regards the mean age of patients in the current study, it was $31 \pm 7$ years which could be due to the susceptibility of this age group to social and economic problems (Kar, 2010). In this study, the female to male ratio was 2.6:1, similar results of increased female to male ratio was reported by (Abdelwahab et al., (2011) and Moghaddam and Pajoumand (2007)). This may be due to liability of females to attempt suicide more than males. Concerning their occupation, half of the patients were unemployed. Most of our patients were from urban areas which were also in accordance with Abdelwahab et al., (2011) who attributed that to the location of PCC-ASUH in Great Cairo, and that patients from rural areas can be presented only in severe cases.

Oral ingestion was the main route of poisoning except in a single accidental case, where inhalation poisoning occurred. This is explained by the availability of the zinc phosphide in the form of powder that can be easily ingested. As regards the manner of poisoning; suicide was the manner of poisoning in all cases except one case in which accidental exposure occurred during pesticide application on grains. This agrees with Mishra et al., (2006) who reported that the majority of cases with zinc phosphide intoxication were suicidal. This may be attributed to its easy availability and low cost.

The majority of the patients presented with delay time between 6-8 hours. This is due to the fact that zinc phosphide is recognized as the slowest acting of the commonly used rodenticide giving the victim time to seek medical advice (Assem and Takayama, 2007)

Nausea, vomiting, abdominal colic and agitation were the initial manifestations. This comes in agreement with El Naggar and El Mahdy (2011) who found abdominal pain and vomiting in $75.8 \%$ of their patients. Nausea and vomiting were common among both survived and non-survived patients in the study done by Hosseinian et al. (2011). This could be attributed to irritation of gastrointestinal tract mucous membrane (Jain et al., 2005).
Systolic blood pressure was low in all cases, but it was significantly lower in patients who died compared to those who survived. Central venous pressure was elevated in 6 patients (all of them died), indicating cardiogenic shock (DeCotiis et al., 2014) Singh et al., (2003)and Akkaoui et al., (2007) reported high CVP and revealed left ventricle hypokinesia by echocardiography in acute aluminum phosphide intoxicated patients. They explained their results to be due to myocardial lesion which might be responsible for hemodynamic failure. Cardiac manifestations in the form of hypotension and arrhythmias were predominant and indicated poor prognosis in the study done by Mathai and Bhanu (2010). However in the current study, shock could be attributed to hypovolemia due to repeated episodes of vomiting or peripheral vasodilatation, which can explain the cause of shock in some of these cases as evidenced by decrease central venous pressure. Although we cannot exclude the cardiac element as in these cases as fluid therapy did not fully correct the shock.

Increased serum levels of (AST) and (ALT) were observed in all patients. However, this was of no significant value. Hepatotoxicity manifested as elevated ALT was found in the studies done by (Karanth and Nayyar (2003), Chomchai (2004), Khurana et al. (2009), and El Naggar and El Mahdy (2011)). Deranged liver function test was associated with poor outcome in the study performed by Hosseinian et al. (2011).

Saleki et al. (2007) stated that phosphine can cause liver dysfunction, especially after the first day of poisoning, and the main histopathological changes found were fine cytoplasmic vacuolization of hepatocytes and sinusoidal congestion. Congestion, edema and centrizonal necrosis of the liver were found on histopathological examination in the study of Musshoff et al. (2008).

Phosphine a nucleophile, acts as a strong reducing agent capable of inhibiting cellular enzymes involved in several metabolic processes. It blocks the enzyme cytochrome $\mathrm{C}$ oxidase as a result of which 
mitochondrial oxidative phosphorylation is inhibited (Singh et al., 2006). It also disturbs the mitochondrial morphology, inhibits respiration by $70 \%$ and causes severe drop in mitochondrial membrane potential, causing in turn, rapid cellular death (Proudfoot, 2009).

All cases in the current study had metabolic acidosis with decreased level of serum bicarbonate. Although serum bicarbonate was lower in the patients who died compared to the patients who survived, yet it was not statistically significant.

Metabolic acidosis was also observed by (Orak et al. (2008), Proudfoot (2009), and El Naggar and El Mahdy (2011)). Hosseinian et al. (2011) considered severe metabolic acidosis as a predictor of mortality. Also, Louriz et al. (2009) considered low serum bicarbonate value (less than $15 \mathrm{mEq} / \mathrm{L}$ ) as a predictor of mortality.

In the current study both groups of patients had normal serum levels of sodium and potassium. Electrolyte disturbance was not found to be an indicator of mortality in a study performed by Mehrotra et al. (2012).

In this study random blood sugar was within normal range. However, Louriz et al. (2009) reported hyperglycemia which was not related to mortality. Mehrotra et al. (2012) in their study found variable random blood sugar levels in patients of acute phosphide poisoning. The difference in random blood sugar between group of survivors and non survivors group was found to be border line, although it was higher among non survivors (Mehrpour et al., 2008). However, Abder-Rahman (1999) in his study reported that hyperglycemia could be used as a prognostic factor in phosphide intoxicated patients.

Direct myocardial injury was evidenced in our study by the finding of increased serum cardiac troponin I. Myocardial muscles injury was demonstrated by Shah et al., (2009) who found that in non survivors patient showed myocyte vacuolation, areas of myocytolysis and degeneration. This finding could be due to myocardial necrosis resulted from the release of reactive oxygen species (Chugh et al., 1997).

Phosphine inhibits mitochondrial cytochrome C oxidase enzyme which may lead to cardiotoxicity. It is also known to inhibit protein synthesis and enzymatic activity, particularly in the mitochondria of heart cells. This can lead to a blockage of mitochondrial electron transport chain (Aggarwal, 2007).

Our finding that half of deaths due to zinc phosphide cardiotoxicity and with negative troponin I represent a significant population at risk and reason for not relying on troponin alone as a predictive of mortality.

Eight patients out of the 18 patients in our study had dysrhythmias, in the form of wide complex ventricular tachycardia, atrial fibrillation, ST segment elevation and diffuse repolarization abnormalities which were predictive of mortality.

Electrocardiographic changes were also detected in other studies performed by Shadnia et al., (2009). Atrial fibrillation, junction rhythm, ventricular and atrial extra systoles and ventricular tachycardia were reported by Gupta et al. (1995). Siwach et al. (1998) reported the incidence of various arrhythmias in aluminum phosphide intoxicated patients in the form of ventricular tachycardia in $40 \%$, ventricular fibrillation, supraventricular tachycardia in $46.7 \%$ and atrial flutter/fibrillation. ST-segment elevations and diffusely abnormal repolarization were found by Akkaoui et al. (2007). Louriz et al. (2009) reported repolarization disorders, such as ST segment depression, ST segment elevation and $\mathrm{T}$ wave inversion.

Katira et al. (1990) showed that during the initial 3-6 hours, sinus tachycardia was predominant, in the 6-12 hours period; ST segment-T wave changes and conduction disturbances were reported.

All the 18 patients under the study were hypotensive despite adequate fluid resuscitation and required vasoactive support, predominantly dopamine and dobutamine. This was in agreement with the findings of Akkaoui et al. (2007) and Mathai and Bhanu (2010).

In our study, mechanical ventilation was required in 6 patients (non survivors). Louriz et al. (2009) considered the need for mechanical ventilation as an indicator of poor outcome.

It is concluded that the overall mortality from zinc phosphide poisoning in the PCC-ASUH during the study period was 12 out of 18 patients. The statistically significant factors which were useful in predicting mortality in our study were increased central venous pressure, shock (which required vasoactive drugs) and ventricular arrhythmias

One of the limitations of this study was our inability to measure the blood level of phosphine, which prevented us from drawing firm conclusions with regard to its temporal relation to cardiotoxicity. However, the consistency of our results with previous studies suggests that phosphide induced cardiotoxicity is the main cause of mortality and morbidity in cases of zinc phosphide poisoning. This cardiotoxicity manifested with refractory shock, ECG changes, and increased serum cardiac troponin I level.

\section{Recommendations}

More policies are needed to restrict the availability and sale of zinc phosphide to limit the magnitude of the problem. Larger prospective studies in the future are needed to support our results. Early sensitive markers of cardiac affection and echocardiography performance are required to detect zinc phosphide cardiotoxicity. Finally further researches to find specific antidote is highly recommended.

\section{References}

Abdelwahab HM, Shalaby SA, Belal SI et al., (2011): Study of zinc phosphide intoxicated cases admitted to Poison Control Centre- Ain Shams University Hospitals-Egypt (A retrospective study). Ain Shams J. Forensic Med.Clin.Toxicol.16:57-67.

Abder-Rahman H. (1999): Effect of aluminum phosphide on blood glucose level. Vet. Hum. Toxicol. 41:31-2. 
Aggarwal P. (2007): Pesticide poisoning. Nat. Med.J.India. 20: 182-91.

Akkaoui M, Achour S, Abidi K et al., (2007): Reversible myocardial injury associated with aluminum phosphide poisoning. Informa Healthcare. 45 (6): 728-31.

Assem L and Takamiya M (2007): Phosphine. In: Toxicological overview, Health Protection Agency, USA,pp: 112-4.

Bazari H (2007): Approach to the patient with renal disease. In: Cecil Medicine, 23 ${ }^{\text {rd }}$ edition, Goldman L and Aussiello D (editors), Saunders Elsevier. Philadelphia; pp: 1720-79.

Bumbrah GS, Krishan K, Kanchan T et al., (2012): Phosphide poisoning: a review of literature. Forens. Sci. Int. 214(1-3): 1-6.

Chomchai S. (2004): Phosphine and phosphides, In: Poisoning and Drug Overdose, K.R. Olson (ed.), 4th ed., Mc Graw Hill, New York, pp. 306-7.

Chugh SN, Kolley T, Kakkar R et al., (1997): A critical evaluation of anti-peroxydant effect of intravenous magnesium in acute aluminium phosphide poisoning. Magnes. Res.10:22530.

Cox CJ (2001): Acute care testing. Blood gases and electrolytes at the point of care. Clin. Lab.Med.J.21(2): 321-35.

DeCotiis C, Danckers M, Roswell RO et al., (2014): The Role of Invasive Hemodynamic Monitoring in an Unusual Case of Refractory Shock. Ann. Am. Thorac.Soc.11: 9: 1497-9

El Naggar ARM and El Mahdy NM (2011): Zinc phosphide toxicity with a trial of tranexamic acid in its management. J. Adv. Res. 2(2): 149-56.

Faix JD (2000): In: Interpretation of Diagnostic Tests; $7^{\text {th }}$ edition; Wallach $\mathrm{J}$ (editor), Lippincott Williams and Wilkins. Philadelphia; pp: 1026.

Gupta MS, Malik A and Sharma VK. (1995): Cardiovascular manifestations in aluminum phosphide poisoning with special reference to echocardiographic changes. J. Assoc. Physicians India. 43:773-4.

Halawa HM, Nageeb SA and El Guindi MK (2013): Annual report of the Poison Control Centre, Ain Shams University Hospitals- Cairo, Egypt, 2012. Ain Shams J. Forensic Med. Clin. Toxicol.21:27-34.

Hosseinian A, Pakravan N, Rafiei Aet al., (2011): Aluminum phosphide poisoning known as rice tablet: A common toxicity in North Iran. Indian J. Med. Sci. 65:143-50.

Jadhav AP, Nusair MB, Ingole A et al., (2012):

Unresponsive ventricular tachycardia associated with aluminum phosphide poisoning. Am J Emerg Med; 30(4):633-5.

Jain M, Nigam SD, Garg A et al., (2005): Aluminium phosphide poisoning autopsy findings. JIAFM. 27: 35-9.

Kar N (2010): Profile of risk factors associated with suicide attempts: A study from Orissa, India. Ind. J.Psych. 52: 48-58.
Karanth S and Nayyar V (2003): Rodenticide-induced hepatotoxicity. J. Assoc. Physicians India. 51:816-7.

Katira R, Elhance GP, Mehrotra ML et al., (1990): A study of aluminium phosphide (ALP) poisoning with special reference to electrocardiographic changes. J. Assoc. Physicians India; 38:471-3.

Khurana V, Gambhir I, and Kishore D. (2009): Microangiopathic hemolytic anemia following disseminated intravascular coagulation in aluminum phosphide poisoning. Indian $\mathrm{J}$. Med. Sci. 63 (6): 257-9.

Lehman R and Krumholz H (2009): Tight control of blood glucose in long standing type 2 diabetes.BMJ; 338-800.

Louriz M, Dendane T, Abidi K et al., (2009): Prognostic factors of acute aluminum phosphide poisoning. Indian J. Med. Sci. 63:227-34.

Marino PL (2010): Shock and inotropic drugs. In: The ICU Book $4^{\text {th }}$ edition, Baltimore William and Wilkins, pp: 461-81.

Mathai A and Bhanu MS. (2010): Acute aluminium phosphide poisoning: Can we predict mortality? Indian J. Anaesth. 54(4): 302-7.

Mehrotra V, Sharma A, Bhatt P et al., (2012): Estimation of serum electrolytes and glucose level in poisoning due to aluminum phosphide. Asian J. Phar. Biol. Res. 2 (2): 153-6.

Mehrpour O, Alfred S, Shadnia S et al., (2008): Hyperglycemia in acute aluminum phosphide poisoning as a potential prognostic factor. Hum. Exp. Toxicol. 27: 591-5.

Mishra S, Shroff S, Shah D (2006): Suicide of farmersin Maharashra. Indira Gandi Institute of development Research, Mumbai.1-130.

Moghaddam H and Pajoumand A (2007): Two years epidemiological survey of aluminium phosphide poisoning in Tehran, Iran.J. Toxicol.37:5-7.

Musshoff F, Preuss J, Lignitz E et al., (2008): A gas chromatographic analysis of phosphine in biological material in a case of suicide. Forensic Sci. Int. 177 (2-3): 35-8.

Nakakita H, Katsumata Y and Ozawa T. (2009): The effect of phosphine on respiration of rat liver mitochondria. Ind. J. Crit. Care Medi. 13: 413.

Nyblom H, Bjornsson E, Simren M et al., (2006): The AST/ALT ratio is an indicator of cirrhosis in patients with primary biliary cirrhosis. Liver Int. J. 26(7): 840-5.

Orak M, Ustundag M, and Sayhan MB. (2008): Severe metabolic acidosis secondary to zinc phosphide poisoning. J. Pak. Med. Assoc. 58 (5): 289-90.

Proudfoot AT. (2009): Aluminium and zinc phosphide poisoning. Clin. Toxicol. Phila. 47:89-100.

Saleki S, Ardalan FA, and Javidan Nejad A. (2007): Liver histopathology of fatal phosphine 
poisoning. Forensic Sci. Int. 166 (2-3): 1903.

Shadnia S, Sasanian G and Allami P (2009): A retrospective 7- years study of aluminium phosphide in Tehran: Opportunities for prevention. Hum. Exp. Toxicol. 28(4): 20913.

Shah V, Baxi S, and Vyas T. (2009): Severe myocardial depression in a patient with aluminium phosphide poisoning: A clinical, electrocardiographical and histopathological correlation. Indian J. Crit. Care Med. 13:41-3.

Singh D, Dewan I, Pandey AN et al., (2003): Spectrum of unnatural fatalities in the Chandigarh zone of northwest India: A 25-year autopsy study from a tertiary care hospital. J. Clin. Forensic Med. 10:145-52.

Singh A, Bhalla SK, Verma A et al., (2006): Cytochrome $\mathrm{C}$ oxidase inhibition in 26 aluminium phosphide poisoned patients. Clin. Toxicol. 44: 155-8.

Siwach SB, Singh H, Sharma D et al., (1998): Cardiac arrhythmias in aluminium phosphide poisoning studied by on continuous Holter and cadioscopic monitoring. J.Assoc. Physicians India. 46: 598-601.

Sue D and Vintch J (2005): Fluids, electrolytes and acid base. In: Current Essentials of Critical Care, Sue D and Vintch J (editors). Lang Medical Books, London; pp: 51-69.

\section{الملخص العربحي}

\section{السمية القلبية فى مرضى التسمم الحاد بفوسفيد الزنك (دراسة مستقبلية)}

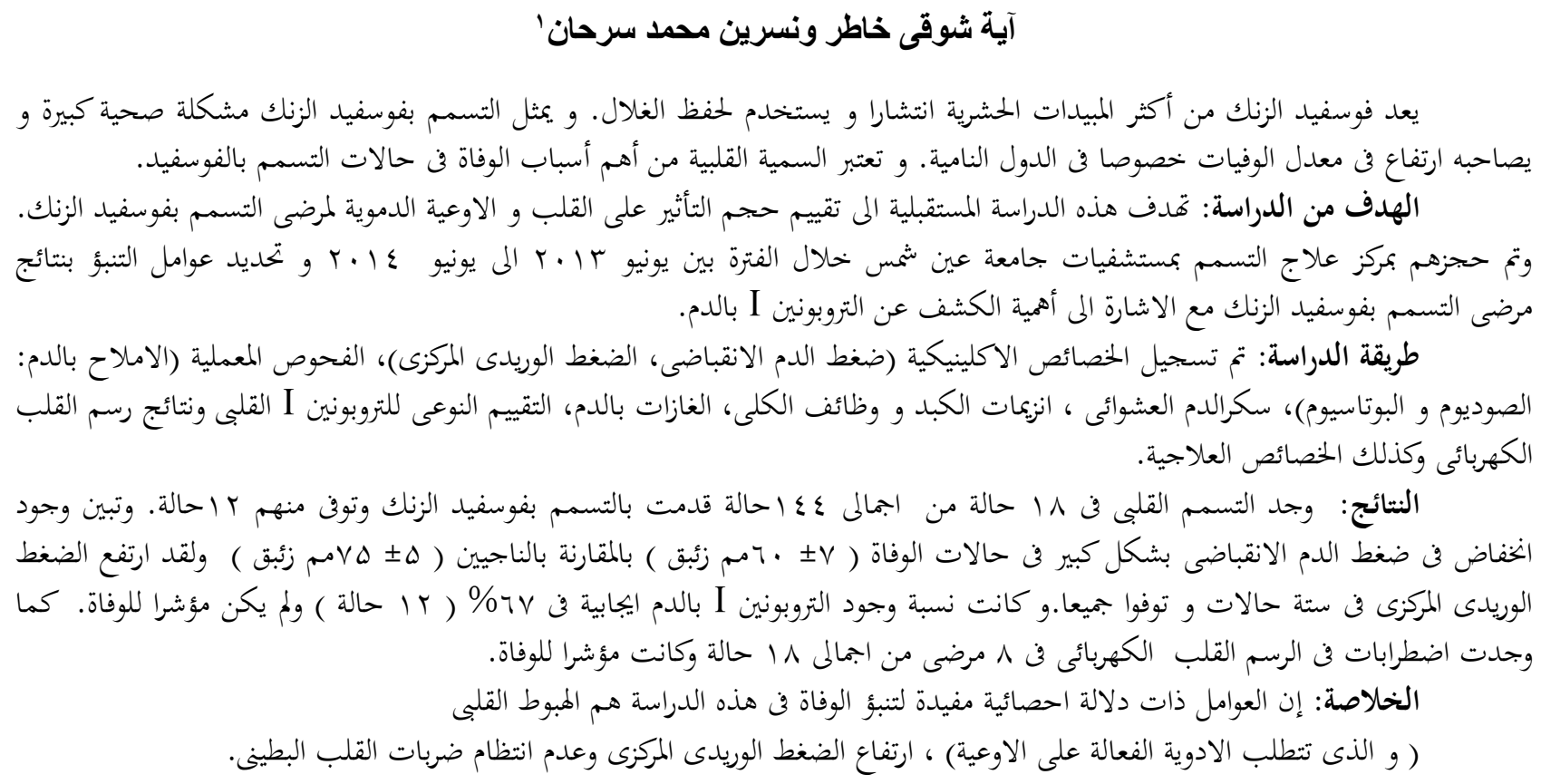

